\title{
Desenvolvimento de doces cremosos de mirtilo e framboesa adicionados de polpa de gila
}

\author{
Sueli Fiorini Sommer', Voltaire Sant'Anna' \\ ' Universidade Estadual do Rio Grande do Sul (UERGS) \\ E-mail: sueli_fsommer@yahoo.com.br, voltaire-santanna@uergs.edu.br
}

Submetido em: 28 set. 2019. Aceito: 04 mar. 2020. DOI: http://dx.doi.org/10.21674/2448-0479.62.132-136

\section{Resumo}

O mirtilo e a framboesa são pequenos frutos ricos em compostos fenólicos e propriedades antioxidantes, que estão ganhando a preferência dos produtores e consumidores. Enquanto que a abóbora gila é uma hortaliça não convencional com propriedades antiglicemiantes, ainda pouco explorada comercialmente. $O$ objetivo deste trabalho foi desenvolver doces cremosos de mirtilo e framboesa, com adição de diferentes proporções de gila, como forma de reduzir custos de produção sem alterar a aceitação sensorial dos doces. O experimento foi realizado na sede da Universidade Estadual do Rio Grande do Sul, unidade de Encantado-RS. Foram adicionadas diferentes proporções de polpa de gila (0, I0, I5 e $20 \%$ ) em doces de mirtilo e de framboesa. Os doces foram submetidos a análises sensoriais e físico-químicas de antocianinas e polifenóis totais. Os doces de mirtilo, além de não apresentarem diferença na concentração de polifenóis totais e de aceitação sensorial, ainda resultaram em maior concentração de antocianinas, em função da adição de gila. Já os de framboesa apresentaram diferenças significativas na avaliação sensorial e redução da concentração de antocianinas, porém não obtiveram redução na concentração de polifenóis totais. Concluiu-se que a adição de polpa de gila é uma opção viável para elaboração de doces cremosos de mirtilo e framboesa, como forma de reduzir custos sem alterar significativamente a aceitação dos produtos.

Palavras-chave: Aceitação. Análise Sensorial. Antocianinas. Polifenóis Totais.

\section{Abstract}

\section{Development of creamy blueberry and raspberry candy added with gila pulp}

Blueberries and raspberries are small fruits rich in phenolic compounds and antioxidant properties, which are catching the preference of producers and consumers. While gila squash is an unconventional vegetable with anti-glycemic properties, it is still underexplored commercially. The objective of this work was to develop creamy blueberry and raspberry candies, with the addition of different gila proportions, as a way to reduce production costs without altering the sensory acceptance of the candies. The experiment was carried out at the headquarters of Universidade Estadual do Rio Grande do Sul, Encantado RS unit. Different ratios of gila pulp (0, 10, 15 and 20\%) were added in blueberry and raspberry jams. The candies were submitted to sensory and physicochemical analyzes of anthocyanins and total polyphenols. The blueberry ones, besides not presenting difference in the total polyphenols concentration and sensory acceptance, also resulted in higher concentration of anthocyanins, due to the addition of gila. Raspberry had significant 
differences in sensory evaluation and reduction of anthocyanin concentration, but no reduction in total polyphenol concentration. It was concluded that the addition of gila pulp is a viable option for making blueberry and raspberry creamy sweets as a way to reduce costs without significantly altering product acceptance.

Keywords: Acceptance. Sensorial Analysis. Anthocyanins. Total Polyphenols.

\section{Introdução}

A produção de pequenos frutos no Brasil tem aumentado na última década, especialmente a partir de produtores de base familiar. A framboesa e o mirtilo são frutos de alto valor agregado que estão ganhando a preferência dos agricultores e dos consumidores devido também a suas características nutracêuticas (RUFATO; ANTUNES, 2016).

Estudos indicam que a presença de compostos fenólicos em mirtilos, framboesas, amoras pretas e morangos proporcionam um efeito benéfico à saúde pela sua ação terapêutica, anti-inflamatória e antioxidante, auxiliando no tratamento de algumas enfermidades como doenças coronarianas e o câncer (BEATTIE et al., 2005; BEEKWILDER et al., 2005 apud GUIMARÃES, 20I2).

A abóbora gila é uma hortaliça pouco convencional de base extrativista ou cultivo de sucessão familiar no Rio Grande do Sul, não existindo sistema produtivo comercial. Segundo Xia e Wang (2007 apud PRIORI et al., 20 10), na Ásia a gila é comumente utilizada como um agente antidiabético e anti-hiperglicemiante. No Brasil, estudos estão sendo desenvolvidos para testar e comprovar essas propriedades.

A crescente demanda por alimentos funcionais, com ingredientes naturais, nutritivos e até mesmo não convencionais, vêm incentivando o lançamento de novos produtos, principalmente, pelas agroindústrias familiares, que se constituem em importantes agentes da economia local.

O desenvolvimento de doces cremosos de mirtilo e de framboesa com polpa de gila proporcionaria a possibilidade de ofertar aos consumidores um produto que aliaria o sabor e as propriedades antioxidantes do mirtilo e da framboesa, com as propriedades antidiabéticas da polpa de gila, agregando características desejadas para um doce cremoso. Além disso, a utilização da abóbora gila traria mais uma aplicabilidade e, principalmente, visibilidade a essa hortaliça não convencional.

Desta forma, o objetivo do presente estudo foi desenvolver doces cremosos de mirtilo e de framboesa com a adição de diferentes proporções de polpa de gila como forma de reduzir custos sem alterar significativamente a aceitação sensorial dos produtos.

\section{Materiais e Métodos}

O experimento foi realizado na Universidade Estadual do Rio Grande do Sul - UERGS, Campus de Encantado-RS. Foram desenvolvidos doces à base de mirtilo e de framboesa com adição de polpa de gila nas proporções de 0, 5, 10, 15 e 20\%. O mirtilo foi adquirido congelado em Putinga-RS. A framboesa foi adquirida congelada em Vacaria-RS. A abóbora gila in natura foi proveniente de Bom Jesus-RS.

Avaliou-se a aceitação sensorial e mediu-se a concentração de antocianinas e fenólicos totais dos diferentes doces produzidos. A quantificação de antocianinas foi determinada por $\mathrm{pH}$ diferencial em soluções tampão de $\mathrm{pH}$ I e $\mathrm{pH} 4,5$. As amostras de mirtilo foram analisadas com fator de diluição 5 (cinco) e as de framboesa, com fator de diluição 2 (dois). $O$ teste foi realizado em triplicata e a leitura feita em espectrofotômetro.

Para a quantificação de polifenóis totais, a análise foi realizada por espectrofotômetro e o teor foi determinado por interpolação da absorbância das amostras contra uma curva de calibração construída com padrão

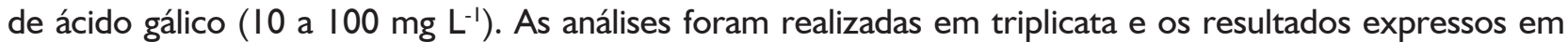
equivalente de ácido gálico (EAG), em $\mathrm{mg} 100 \mathrm{~g}^{-1}$. As análises sensoriais foram realizadas em espaço reservado, utilizando um painel de 52 provadores, de ambos os sexos, de idades de 18 a 60 anos, que avaliaram os atributos textura, cor, doçura, acidez, sabor de mirtilo ou framboesa e aceitação global, através de uma escala hedônica estruturada de 7 pontos, que representa variação de "gostei muitíssimo" (7) até "desgostei muitíssimo" (I). No mesmo momento foi feita uma análise de intenção de compra variando de "compraria" (3), "talvez compraria” (2) e "não compraria” (I) (INSTITUTO ADOLFO LUTZ, 2008).

Os dados obtidos foram analisados através da análise de variância e, quando pertinente, o teste de Tukey, a uma significância de 5\%, foi realizado para discernir diferenças entre as médias. 


\section{Resultados e Discussão}

$\mathrm{Na}$ condução do estudo, considerou-se que a adição de polpa de gila poderia afetar o teor de antocianinas e polifenóis, bem como a aceitação sensorial dos doces. Torna-se relevante inferir que os resultados demonstraram que não houve perda significativa de polifenóis totais. Apenas nos doces de framboesa observou-se uma redução nas antocianinas, o que se justifica pelo fato de que as formulações com maior percentual de polpa de gila, por serem menos ácidas, demandaram maior tempo de cozimento, e, consequentemente, sofreram maior degradação ao longo do processo de cozimento.

Segundo Lovatto (2016), uma cocção prolongada pode causar uma excessiva inversão da sacarose e degradação da pectina, ocasionando uma perda nutricional que interfere na textura.

Nos doces cremosos de mirtilo a menor concentração de antocianinas encontrou-se na formulação sem adição de gila, enquanto que a maior concentração encontrou-se na formulação com $20 \%$ de gila. O resultado se justifica pelo fato de que o maior tempo de cozimento demandado para atingir o ponto de doce cremoso, conseguiu extrair eficientemente as antocianinas que se encontravam predominantemente na casca do fruto. Esse resultado é condizente com valores encontrados por Rocha (2009), que avaliou polpa e extrato de mirtilo e encontrou $58,95 \mathrm{mg} / \mathrm{l} 00 \mathrm{~g}$ de antocianinas totais na polpa e $1182 \mathrm{mg} / \mathrm{l} 00 \mathrm{~g}$ no extrato da casca.

Os resultados da análise e quantificação de antocianinas e polifenóis totais presentes nos doces cremosos de mirtilo e framboesa estão expressos na Tabela I.

Em relação aos polifenóis totais, ambos os doces não sofreram alteração significativa em função da adição de polpa de gila. Já em relação à quantidade de antocianinas, os doces cremosos de framboesa apresentaram diferença significativa entre as formulações, com redução na ordem de $24,3 \%$ para a amostra com 20 \% de gila em relação a não adicionada de gila.

Tabela I. Resultados da quantificação de antocianinas e polifenóis totais nos doces cremosos de mirtilo e framboesa.

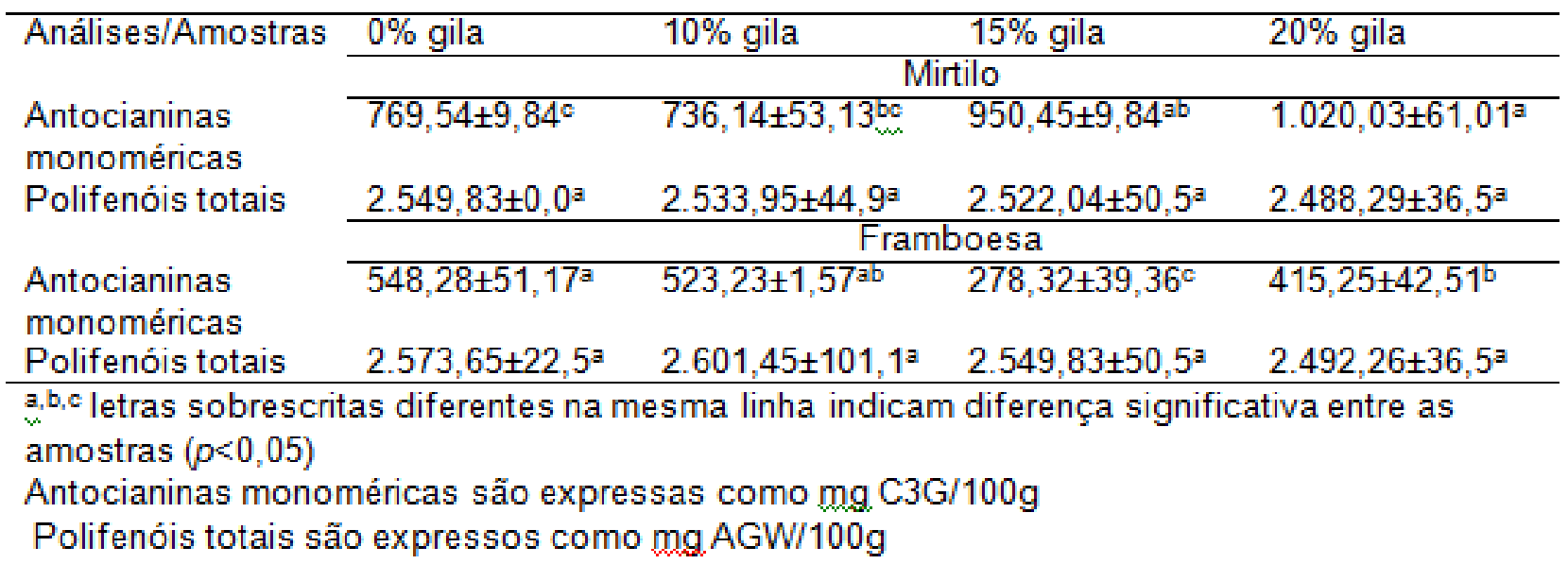

Fonte: Autores, (2018)

As análises sensoriais demonstraram que os doces cremosos de mirtilo que continham 10\%, 15\% e 20 \% de polpa de gila, não apresentaram diferença significativa em relação à amostra sem gila, nos atributos "textura", "doçura", "acidez", "sabor de mirtilo" e "aceitação global".

No atributo "cor" a amostra com 10\% de gila obteve a maior média e se diferenciou das demais com $15 \%$ e $20 \%$ de gila.

Os resultados da manifestação da "intenção de compra" dos provadores, expressos em percentuais, constam na Figura I. A análise estatística também demonstrou não haver diferença significativa entre as amostras para esse quesito.

Em relação à aceitação sensorial, o melhor resultado se obteve nos doces de mirtilo, que não apresentaram diferença significativa entre as amostras, na maioria dos atributos avaliados. Todavia, cabe relatar que a amostra com $10 \%$ de gila, além de ter se destacado positivamente das demais com $15 \%$ e $20 \%$ de gila, no atributo "cor", ocorreu que na "intenção de compra" também obteve o maior percentual de provadores que a "comprariam" em relação à amostra sem adição de gila. Deduz-se, portanto, que a adição de polpa de gila resultou em uma melhor aceitação e intenção de compra do produto, não confirmando a hipótese do trabalho proposto. 
Em estudo anterior, Guimarães (20I4) realizou análise sensorial de geleia de mirtilo em diversas formulações, com versões tradicionais, light e adicionados de dois tipos de pectina. Constatou que em relação à cor e ao sabor, a maior preferência dos provadores foi pelos produtos convencionais, ou seja, mais doces, adicionados de pectina e pectina de casca de maracujá. Dessa forma, por um lado, o resultado obtido no presente trabalho se contrapõe ao estudo anterior, uma vez que a preferência apontou para uma formulação de produto não convencional. Por outro lado, também pode se inferir alguma coerência entre os resultados, já que a preferência dos provadores, no presente estudo, também recaiu sobre uma formulação, na qual a adição da polpa de gila diminuiu a acidez, amenizou o sabor silvestre e exótico do mirtilo, evidenciando de forma mais proeminente, o sabor doce do fruto e do produto.

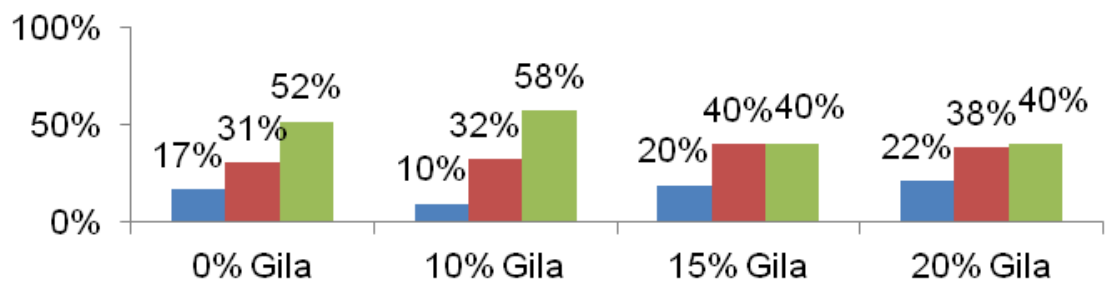

Fonte: Autores, (2018).

\author{
Figura I \\ Manifestação da intenção de compra \\ dos provadores para os doces cremosos \\ de mirtilo com polpa de gila. \\ 1- Não compraria \\ 2-Talvez compraria \\ 3-Compraria
}

Os resultados da análise sensorial do doce cremoso de framboesa com polpa de gila, em suas diferentes formulações indicaram diferença significativa para a maioria dos atributos avaliados, com exceção da "acidez".

Nos atributos de "doçura", "sabor de framboesa" e "aceitação global" os resultados mostraram uma menor aceitação das amostras que continham gila em comparação com a sem gila, sem que houvesse, no entanto, diferença significativa entre as diferentes formulações com gila.

Em relação à "intenção de compra", cujos resultados estão expressos em percentuais na Figura 2, observou-se que apesar de não haver diferença significativa entre as amostras com acréscimo de gila, aquela com $10 \%$ também não apresentou diferença significativa em relação à amostra sem gila.

Além da perda em antocianinas, a adição de gila também afetou a aceitação sensorial nos doces cremosos de framboesa, confirmando a hipótese inicial do estudo. Porém, há de se considerar que, em relação à "intenção de compra", as amostras com 10\%, 15\% e 20\% de gila não apresentaram diferenças significativas entre si. Além disso, aquela com 10\% de gila não apresentou diferença significativa em relação à que não continha gila.

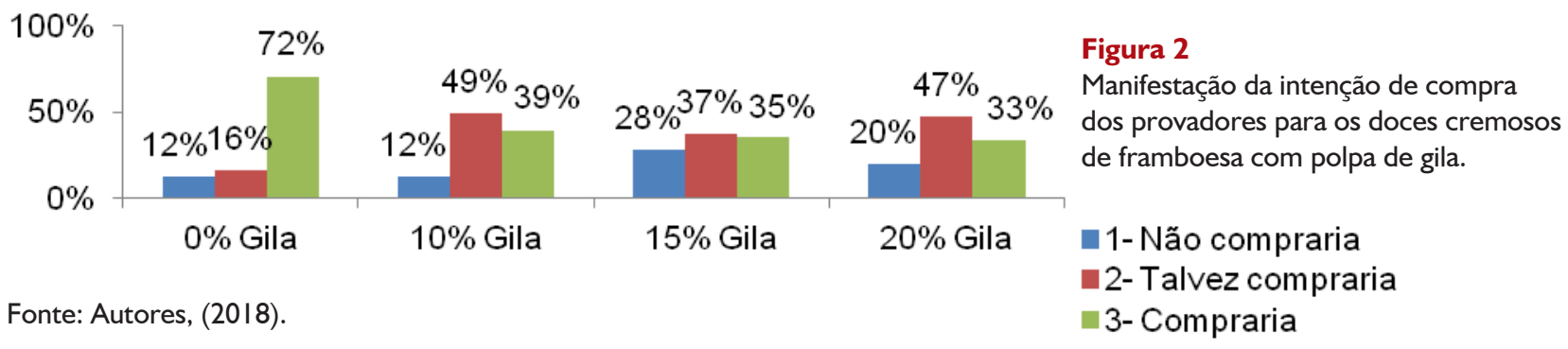

\section{Conclusão}

Diante do estudo realizado, observou-se que os doces cremosos de mirtilo obtiveram uma boa aceitação, pois não apresentaram diferenças significativas entre as amostras. Até mesmo no caso da framboesa os resultados foram satisfatórios, haja vista a preservação do teor de fenólicos totais e da manifestação de intenção positiva de compra dos provadores, mais especificamente para a formulação com $10 \%$ de gila.

Portanto, concluiu-se que é possível produzir doces cremosos de pequenos frutos utilizando a polpa de gila em suas formulações reduzindo custos, sem alterar significativamente a aceitação sensorial dos produtos e sem causar perdas significativas de antocianinas e fenólicos totais. 


\section{Referências}

GUIMARÃES, I. C. Tecnologias para conservação e processamento de framboesa (Rubus idaeus). 20I2. Dissertação (Mestrado) - Universidade Federal de Lavras (UFL), Lavras, 2012. Disponível em: http://repositorio.ufla.br/ bitstream/l/I I 76/I/DISSERTA\%C3\%87\%C3\%830_Tecnologias\%20para\%20conserva\%C3\%A7\%C3\%A3०\%20 e\%20processamento\%20de\%20framboesa\%20\%28Rubus\%20idaeus\%29.pdf. Acesso em: 09 set. 2018.

GUIMARÃES, D. H. P. et al. Geleia de mirtilo (Blueberry): análises dos parâmetros sensoriais e do efeito do armazenamento nas propriedades físicas e químicas. Revista Brasileira de Pesquisa em Alimentos (REBRAPA). Campo Mourão, v. 5, n. I, p. 19-25, 2014. Disponível em: http://cm.utfpr.edu.br/files_old/files/journals/I/articles/I50/attachment/I50-883-I-AT.pdf. Acesso em: 26 mai. 2018.

INSTITUTO ADOLFO LUTZ. Métodos físico-químicos para analise de alimentos. 4. ed. São Paulo: Instituto Adolfo Lutz, 2008. Disponível em: http://www.ial.sp.gov.br/resources/editorinplace/ial/2016_3_19/analisedealimentosial_2008.pdf. Acesso em: 28 de jun. 2018.

LOVATTO, M. T. Agroindustrialização de frutas I. Santa Maria: Universidade Federal de Santa Maria; Colégio Politécnico; Rede e-Tec Brasil, 2016. Disponível em: http://estudio0I.proj.ufsm.br/cadernos_fruticultura/sexta_etapa/arte_ agroindustrializacao_de_frutas_l.pdf. Acesso em: 28 mai. 2018.

PRIORI, D. et al. Abóbora-gila (cucurbita ficifolia), uma hortaliça pouco convencional cultivada no Rio Grande do Sul. Pelotas: Embrapa Clima Temperado, 2010. Disponível em: https://ainfo.cnptia.embrapa.br/digital/bitstream/ item/78979/1/documento-320.pdf. Acesso em: 2 abr. 2018.

ROCHA, F. I. G. Avaliação da cor e da atividade antioxidante da polpa e extrato de mirtilo (Vaccinium myrtillus) em pó. Dissertação (Mestrado) - Universidade Federal de Viçosa. Viçosa, 2009. Disponível em: http://www.locus. ufv.br/bitstream/handle/I23456789/2865/texto\%20completo.pd?sequence=I. Acesso em: 10 nov. 2018.

RUFATO A. D. R.; ANTUNES L. E. C. (Ed.). Técnicas de produção de framboesa e Mirtilo. Brasília: Embrapa Clima Temperado, 2016. Disponível em: https://www.embrapa.br/busca-de-publicacoes/-/publicacao/I074452/tecnicas-de-producao-de-framboesa-e-mirtilo. Acesso em 16 nov. 2018. 